\title{
Caracterização e atributos da vegetação herbácea em um fragmento de Caatinga no Estado de Sergipe, Brasil ${ }^{1}$
}

\author{
(DEduardo Vinícius da Silva Oliveira ${ }^{2,4}$, Ana Paula do Nascimento Prata ${ }^{3}$ e Alexandre de Siqueira Pinto ${ }^{2}$
}

Recebido: 3.10.2017; aceito: 16.02 .2018

\begin{abstract}
Characterization and attributes of herbaceous vegetation in a Caatinga fragment in the State of Sergipe, Brazil). Variations in environmental factors are expected to be responsible for the diversification of herbaceous plants in the Caatinga (dry forest). We analyzed the composition, floristic similarity and structure of the herbaceous vegetation in a Caatinga fragment in the municipality of Poço Verde, Sergipe State, Brazil. In addition, the influence of precipitation on richness among different Caatinga areas was evaluated. We installed 30 subplots and the floristic composition was complemented by collections made around these subplots. A total of 80 species were found, of which $43 \%$ are typically from disturbed areas of Caatinga. Among the Caatinga areas, precipitation did not explain the variation of richness; similarity values were determined by environmental heterogeneity. The parameters of Shannon-Wiener diversity and Pielou's evenness were within the range expected for Caatinga disturbed areas. Based on evidence supported by previous studies, we believe that human disturbance influences the composition and the structure of the studied herbaceous vegetation. Therefore, conservation actions are recommended.
\end{abstract}

Keywords: floristic, floristic similarity, human disturbance, phytosociology

RESUMO - (Caracterização e atributos da vegetação herbácea em um fragmento de Caatinga no Estado de Sergipe, Brasil). Espera-se que variações nos fatores ambientais sejam responsáveis pela diversificação das plantas herbáceas na Caatinga. Nesta pesquisa, objetivou-se caracterizar a vegetação herbácea quanto à composição, similaridade e estrutura, em um fragmento de Caatinga em Poço Verde, Estado de Sergipe, Brasil. Além disso, avaliou-se a influência da precipitação na riqueza entre diferentes áreas de Caatinga. A amostragem foi realizada por meio de 30 subparcelas, além de coletas adicionais de plantas no seu entorno. Foram encontradas 80 espécies, sendo $43 \%$ típicas de áreas antropizadas de Caatinga. Entre as áreas de Caatinga, a precipitação não explicou a variação de riqueza; os valores de similaridade foram determinados pela heterogeneidade ambiental. A diversidade Shannon-Wiener e a equabilidade de Pielou encontraram-se dentro da faixa esperada para áreas antropizadas de Caatinga. Com base em evidências suportadas por outros estudos, acredita-se que a antropização modificou a estrutura e a composição da vegetação herbácea, razão pela qual se recomendam ações de conservação.

Palavras-chave: antropização, fitossociologia, florística, similaridade florística

\section{Introdução}

A maior parte dos estudos relacionados à vegetação na Caatinga engloba a comunidade arbustivo-arbórea, ou seja, poucos têm enfatizado a comunidade herbácea (Pessoa et al. 2004, Araujo et al. 2005, Costa et al. 2007, Andrade et al. 2009) e por isso, esse estrato é bem menos conhecido (Reis et al. 2006) e pouco considerado em estratégias de conservação (Araujo et al. 2005). Além disso, a maior parte destes estudos concentra-se em poucos Estados, como Pernambuco (Pessoa et al. 2004, Araujo et al. 2005, Rodal et al. 2005, Reis et al. 2006, Pereira et al. 2008, Silva et al. 2009, Feitoza 2013, Santos et al. 2013, Silva et al. 2013a), Rio Grande do Norte (Maracajá \& Benevides 2006, Queiroz 2006, Santos et al. 2006, Benevides et al. 2007, Miranda et al. 2007, Costa et al. 2016), Paraíba (Sizenando-Filho et al.

1. Parte da Dissertação de Mestrado do primeiro Autor

2. Universidade Federal de Sergipe, Programa de Pós-Graduação em Ecologia e Conservação, Av. Marechal Rondon, s/n, Jardim Rosa Elze, 49100-000, São Cristóvão, SE, Brasil

3. Universidade Federal de Alagoas, Centro de Ciências Agrárias, BR-104 Norte km 85, s/n, Mata do Rolo, 57100-000, Rio Largo, AL, Brasil

4. Autor para correspondência: eduardovso@yahoo.com.br 
2007, Andrade et al. 2009, Silva 2011, Silva et al. 2012) e Ceará (Costa et al. 2007, Ribeiro-Filho et al. 2015).

Sergipe é um Estado que ilustra bem o pouco conhecimento disponível referente às herbáceas da Caatinga, pois neste Estado foi verificado apenas um levantamento florístico e fitossociológico, realizado especificamente com este estrato (Oliveira et al. 2013). Entretanto, ainda existe uma lacuna sobre as relações de similaridade florística entre as herbáceas da Caatinga em Sergipe com outras áreas dessa vegetação na região Nordeste. As variações na composição florística entre diferentes áreas de Caatinga estão determinadas em grande parte, pelo clima, relevo e embasamento geológico que, em suas múltiplas inter-relações, resultam em ambientes ecológicos distintos (Rodal et al. 2008). A realização de estudos com o estrato herbáceo da Caatinga em diferentes regiões desta vegetação em Sergipe permite conhecer as variações estruturais desse estrato em resposta a diferentes fatores ambientais.

Dos estudos realizados sobre as herbáceas na Caatinga, pode-se afirmar que se trata de um estrato efêmero e dominado por plantas terófitas e geófitas (Rizzini 1997, Prado 2008, Queiroz 2009). No entanto, as terófitas predominam como a principal estratégia de sobrevivência neste estrato (Pessoa et al. 2004, Rodal et al. 2005, Costa et al. 2007, Silva et al. 2009, Oliveira et al. 2013). Nesta vegetação, sabe-se ainda que muitas herbáceas florescem apenas no período chuvoso (Pereira et al. 1989), que a variabilidade climática interanual modifica temporalmente a estrutura e a composição florística deste estrato (Reis et al. 2006, Silva 2011, Santos et al. 2013) e que estes mesmos parâmetros variam entre micro-habitats específicos (Araujo et al. 2005, Silva et al. 2013a). Contudo, ainda é necessário o surgimento de estudos que visem contribuir para o conhecimento ecológico da vegetação herbácea de Caatinga (Oliveira et al. 2013), como por exemplo, o papel da precipitação na riqueza entre diferentes áreas. Essa relação é conhecida para a vegetação lenhosa, sendo esperado um incremento na riqueza florística com aumento da precipitação pluvial (Andrade-Lima 1981, Ramalho et al. 2009).

Em relação à relevância ecológica do estrato herbáceo da Caatinga, pode-se citar a elevada riqueza biológica (Araujo et al. 2005, Queiroz 2006, Costa et al. 2007, Silva et al. 2012, Feitoza 2013), inclusive em maior proporção que o estrato lenhoso (Costa et al. 2007). Além disto, as herbáceas possuem um importante papel na manutenção do estrato lenhoso da Caatinga (Silva et al. 2009), pois, além de influenciar a sua dinâmica (Lima 2011), mantém ainda condições de germinação para este estrato, através da proteção e do sombreamento do solo (Reis et al. 2006, Vieira \& Scariot 2006, Silva 2011).

A composição florística e a estrutura de comunidades herbáceas estão condicionadas a alguns fatores, provavelmente não mutuamente excludentes, como por exemplo, altitude, declividade, fertilidade do solo e precipitação (Costa 2004, Costa et al. 2005, Inácio \& Jarenkow 2008, Lima \& Gandolfi 2009). Entretanto, as atividades antrópicas também podem ser consideradas como um fator influenciador da estrutura (por exemplo, riqueza de espécies e de famílias, densidade, diversidade Shannon-Wiener, equabilidade de Pielou e área basal) e da composição das comunidades herbáceas da Caatinga (Santos et al. 2006, Benevides et al. 2007, Miranda et al. 2007, Sizenando-Filho et al. 2007, Andrade et al. 2009, Silva 2011, Feitoza 2013). Em ambientes antropizados, existe uma maior disponibilidade de luz, modificando a estrutura do estrato herbáceo (Santos et al. 2006, Benevides et al. 2007, Sizenando-Filho et al. 2007, Silva 2011, Zelarayán et al. 2015). Apesar de evidências mostrarem que o desenvolvimento deste estrato é limitado pelo sombreamento (Inácio \& Jarenkow 2008, Lima \& Gandolfi 2009, CitadiniZanetti et al. 2011), ilhas de vegetação perene podem facilitar o estabelecimento de plantas herbáceas na Caatinga (Silva et al. 2015).

Diante do exposto, este estudo foi realizado em um fragmento de Caatinga no município de Poço Verde, centro-sul de Sergipe, com o objetivo de caracterizar a vegetação herbácea quanto à composição, estrutura e similaridade florística com outras áreas de Caatinga da região Nordeste. Além disso, através de uma meta-análise foi avaliada a influência da precipitação na riqueza entre diferentes áreas de herbáceas da Caatinga. Com este estudo, procurou-se responder as seguintes perguntas: (i) a antropização existente no fragmento possui influência na composição e estrutura da vegetação?; (ii) a similaridade/dissimilaridade florística entre áreas de Caatinga é determinada pela distância geográfica ou fatores ambientais?; e (iii) a precipitação possui influência na riqueza entre diferentes áreas de Caatinga?

\section{Material e métodos}

Área de estudo - O estudo foi conduzido em um fragmento de Caatinga Hipóxerofila (Anholetto- 
Jr. 2013) de 71,42 ha (figura 1), localizado no assentamento Santa Maria da Lage $\left(10^{\circ} 44^{\prime} 31^{\prime \prime} \mathrm{S}\right.$ e $38^{\circ} 05^{\prime} 53^{\prime}$ 'O), município de Poço Verde, região centro-sul de Sergipe. Este fragmento é caracterizado por uma fitofisionomia florestal densa e seca, com subbosque fechado, atualmente em estágio de regeneração após perturbações antrópicas pretéritas, como por exemplo, extração de madeira (Anholetto-Jr. 2013, Ferreira et al. 2013).

De acordo com a classificação climática de Köppen, o clima da região é do tipo As, com estação chuvosa no inverno (SEPLAG-SE 2011, Álvares et al. 2014). A temperatura média anual é de $23,7^{\circ} \mathrm{C}$, com uma precipitação anual média de $780 \mathrm{~mm}$ e o período chuvoso concentrado de abril a julho (SEPLANTECSE 1997, SEPLAG-SE 2011).

A região de estudo está inserida no pediplano sertanejo e apresenta superfícies dissecadas e serras

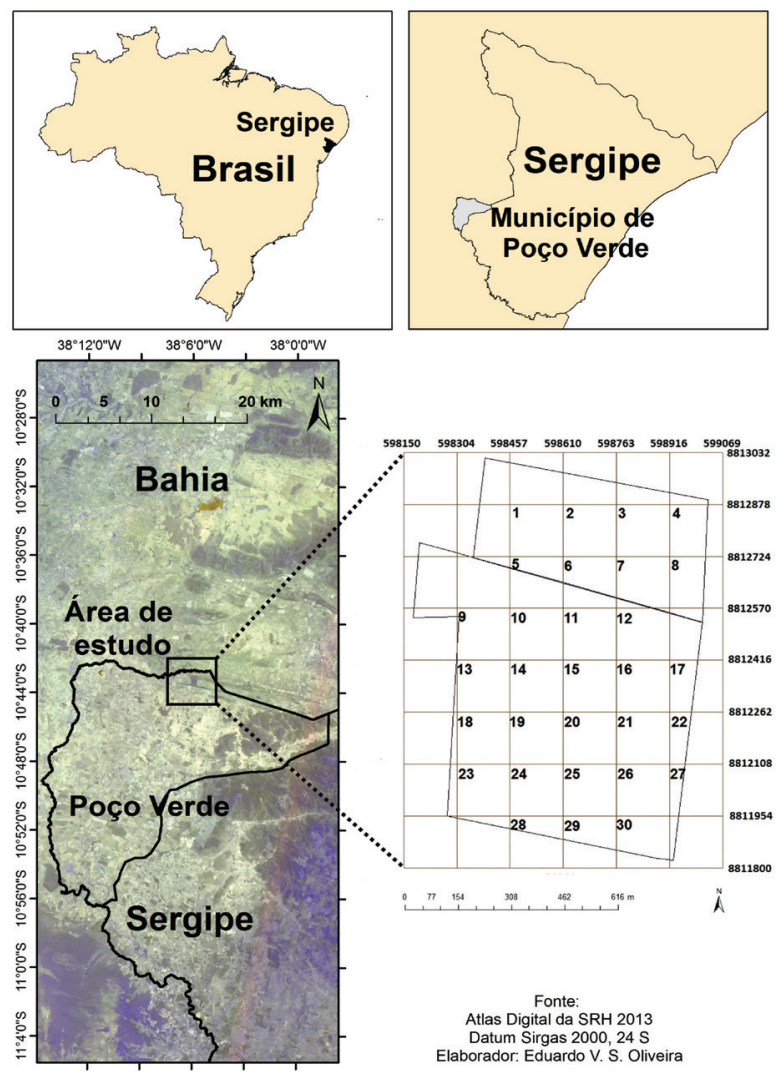

Figura 1. Localização da área de estudo e distribuição dos vértices georreferenciados das parcelas permanentes instaladas (adaptado de Ferreira 2011) no fragmento de Caatinga, município de Poço Verde, centro-sul de Sergipe, Brasil.

Figure 1. Study site and distribution of the georeferenced vertices of the permanent plots installed (adapted from Ferreira 2011) in the Caatinga fragment, municipality of Poço Verde, south-central region of Sergipe State, Brazil. residuais numa altitude de $273 \mathrm{~m}$ (SEPLAG-SE 2014). $\mathrm{O}$ solo do fragmento estudado é classificado como eutrófico e apresenta textura franco-argilosa (Oliveira 2016).

Coleta de dados - Para a amostragem fitossociológica foram utilizadas 30 parcelas permanentes de $20 \times 20$ $\left(400 \mathrm{~m}^{2}\right)$ instaladas anteriormente na área de estudo (Ferreira 2011). Os vértices destas parcelas foram distribuídos de acordo com o intervalo de amostragem $\mathrm{K}(154 \mathrm{~m})$ - obtido pela raiz quadrada da divisão da área total pelo número de parcelas permanentes - num software de SIG (sistema de informações geográficas). A partir dos vértices georreferenciados, cada parcela foi montada medindo $20 \mathrm{~m}$ em direção ao sul e $20 \mathrm{~m}$ em direção ao leste (figura 1).

Dentro das parcelas, foram montadas 30 subparcelas de $1 \times 1\left(1 \mathrm{~m}^{2}\right)$ a uma distância de $10 \mathrm{~m}$ a partir do vértice georreferenciado de cada parcela, seguindo um ângulo de $45^{\circ}$ (RMFC 2005). Foram considerados como herbáceos todos os indivíduos presentes nas subparcelas que apresentaram caule verde, com ausência ou baixo nível de lignificação. Para esses indivíduos, o diâmetro ao nível do solo (DAS) do caule ou pseudocaule foi mensurado com auxílio de um paquímetro digital. Para indivíduos com perfilhos, cada um foi contabilizado individualmente; plântulas e juvenis do componente lenhoso não foram amostrados. Estes foram identificados através de método visual, com auxílio de lupa, considerando atributos morfológicos (por exemplo, Pereira \& Secorun 2001). As medições foram realizadas entre março e setembro de 2015, ou seja, do período chuvoso até o pico da estação seca. Para cada subparcela amostrada, incluindo o seu entorno, avaliou-se o estado de conservação por meio do registro da presença ou ausência de impactos antrópicos (por exemplo, queimadas, extração de madeira, pastejo, etc.).

Coletas de material botânico foram realizadas tanto no interior, como no entorno das subparcelas no período de setembro/2014 a março/2016, à procura de espécimes em estádio reprodutivo. As amostras foram herborizadas segundo os métodos usuais (Mori et al. 1985) e encaminhadas para o Herbário da Universidade Federal de Sergipe - ASE (Thiers 2016), para identificação, registro e posterior incorporação ao acervo. A identificação foi realizada com base em literatura especializada (Souza \& Lorenzi 2012, Prata et al. 2013, 2015), chaves taxonômicas, comparação com as exsicatas presentes no acervo do Herbário 
ASE e quando necessário, através de consulta a especialistas. O sistema de classificação adotado foi o Angiosperm Phylogeny Group IV (2016) e a nomenclatura dos táxons seguiu a Flora do Brasil (2020) em construção.

Análise de dados - Para o levantamento da estrutura horizontal foram estimados os seguintes parâmetros fitossociológicos (Mueller-Dombois \& Ellemberg 1974): densidade, frequência, dominância e valor de importância (VI). A seguir foi calculado o índice de diversidade Shannon-Wiener $\left(\mathrm{H}^{\prime}\right)$ e a equabilidade de Pielou (J) com o auxílio do programa Fitopac 2.2 (Shepherd 2010).

A relação da riqueza com a precipitação anual média $(\mathrm{mm})$ foi avaliada através dos dados de 15 estudos realizados com o estrato herbáceo em áreas de Caatinga. Inicialmente, foi realizado teste de ShapiroWilk, seguido da correlação de Spearman $\left(\mathrm{r}_{\mathrm{s}}\right)$, sendo ambas as análises realizadas no aplicativo Past 2.17 (Zar 2010, Hammer et al. 2013).

Para o cálculo de similaridade florística, foram selecionadas seis publicações abrangendo listas de espécies do componente herbáceo da Caatinga (Reis et al. 2006, Benevides et al. 2007, Sizenando-Filho et al. 2007, Andrade et al. 2009, Silva et al. 2012, Oliveira et al. 2013). Dentre os escassos estudos florísticos realizados com a vegetação herbácea na Caatinga, foram mantidos apenas aqueles com metodologia de coleta semelhante a este estudo. A seguir, utilizando o índice de Sørensen $\left(\mathrm{I}_{\mathrm{s}}\right)$, foi gerado um dendograma a partir de uma matriz binária (presença/ausência) com a distribuição das espécies registradas neste e nos estudos selecionados utilizando média aritmética não ponderada por grupo (UPGMA) no aplicativo Past 2.17 (Hammer et al. 2013).

Para avaliar a correlação entre a similaridade florística e a distância geográfica entre as áreas de Caatinga analisadas, foi realizado teste de Mantel usando o índice de correlação de Pearson e a seguir o teste de Monte Carlo com 5000 permutações aleatórias $(\alpha=0,05)$ no aplicativo Past 2.17 (Zar 2010, Hammer et al. 2013). A matriz de distância linear entre as áreas de Caatinga analisadas foi gerada no aplicativo ArcGIS 9.3 (ESRI 2002).

\section{Resultados e Discussão}

Foram encontradas 80 espécies, distribuídas em 72 gêneros e 34 famílias (tabela 1). Esses valores correspondem a $4 \%, 10 \%$ e $27 \%$ de espécies, gêneros e famílias, respectivamente, dos números totais estimados para a Caatinga (stricto sensu) (Flora do Brasil 2020 em construção), numa área que

Tabela 1. Flora herbácea registrada para o fragmento de Caatinga no município de Poço Verde, centro-sul de Sergipe, com os parâmetros estruturais de famílias e espécies amostradas no levantamento fitossociológico (em ordem decrescente de VI por família). DR: densidade relativa, FR: frequência relativa, DoR: dominância relativa, VI: valor de importância, FV: forma de vida, ER: erva, SA: subarbusto, LVT: liana/volúvel/trepadeira, S: substrato, E: epífita, R: rupícola, T: terrícola, He: hemiepífita.

Table 1. Herbaceous flora recorded for the Caatinga fragment in the municipality of Poço Verde, Sergipe State, Brazil, with structural parameters of families and species sampled in the phytosociological analysis (in descending order of VI per family). DR: relative density, FR: relative frequency, DoR: relative dominance, VI: importance value, FV: habit, ER: herb, SA: subshrub, LVT: liana/scandent/vine, S: substrate, E: epiphytic, R: rupiculous, T: terrestrial, He: hemiepiphytes.

\begin{tabular}{lcccccc}
\hline Família/Espécie & DR & FR & DoR & VI & FV/S & Voucher (ASE) \\
\hline Samambaias & - & - & - & - & - & - \\
$\quad$ Polypodiaceae & - & - & - & - & - & - \\
$\quad$ Pleopeltis sp. & - & - & - & - & ER/E & 35398 \\
$\quad$ Selaginellaceae & - & - & - & - & - & - \\
$\quad$ Selaginella convoluta (Arn.) Spring & - & - & - & - & ER/R & 32002 \\
Angiospermas & - & - & - & - & - & - \\
$\quad$ Bromeliaceae & 1,54 & 6,84 & 86,99 & 95,37 & - & - \\
$\quad$ Aechmea aquilega (Salisb.) Griseb. & 0,41 & 2,14 & 72,55 & 75,11 & ER/T & 33343 \\
$\quad$ Bromelia laciniosa Mart. ex Schult. \& Schult.f. & 1,13 & 3,57 & 14,43 & 19,13 & ER/T & 34477 \\
$\quad$ Aechmea lingulata (L.) Baker & - & - & - & - & ER/T & 35011
\end{tabular}


Tabela 1 (continuação)

\begin{tabular}{|c|c|c|c|c|c|c|}
\hline Família/Espécie & DR & FR & DoR & VI & $\mathrm{FV} / \mathrm{S}$ & Voucher (ASE) \\
\hline Bromeliaceae & - & - & - & - & - & - \\
\hline Neoglaziovia variegata (Arruda) Mez & - & - & - & - & $\mathrm{ER} / \mathrm{T}$ & 34479 \\
\hline Tillandsia gardneri Lindl. & - & - & - & - & $\mathrm{ER} / \mathrm{E}$ & 33344 \\
\hline Tillandsia polystachia (L.) L. & - & - & - & - & $\mathrm{ER} / \mathrm{E}$ & 33345 \\
\hline Asteraceae & 49,90 & 13,68 & 1,72 & 65,29 & - & - \\
\hline Ageratum conyzoides L. & 38,30 & 7,14 & 0,56 & 46,01 & $\mathrm{SA} / \mathrm{T}$ & 32003 \\
\hline Blainvillea acmella (L.) Philipson & 9,75 & 2,14 & 1,11 & 13,01 & $\mathrm{ER} / \mathrm{T}$ & 36135 \\
\hline Centratherum punctatum Cass. & 1,23 & 2,86 & 0,01 & 4,11 & $\mathrm{SA} / \mathrm{T}$ & 35001 \\
\hline Bidens pilosa $\mathrm{L}$ & 0,31 & 1,43 & $<0,01$ & 1,74 & $\mathrm{ER} / \mathrm{T}$ & 35009 \\
\hline Trixis antimenorrhoea (Schrank) Kuntze & 0,21 & 0,71 & $<0,01$ & 0,93 & $\mathrm{SA} / \mathrm{T}$ & 31993 \\
\hline Lepidaploa remotiflora (Rich.) H. Rob. & 0,10 & 0,71 & $<0,01$ & 0,82 & $\mathrm{SA} / \mathrm{T}$ & 32012 \\
\hline Melanthera latifolia (Gardner) Cabrera & - & - & - & - & $\mathrm{ER} / \mathrm{T}$ & 34752 \\
\hline Poaceae & 23,40 & 9,40 & 0,34 & 33,16 & - & - \\
\hline Paspalum fimbriatum Kunth & 13,60 & 7,14 & 0,22 & 21,02 & $\mathrm{ER} / \mathrm{T}$ & 34748 \\
\hline Panicum sp. & 4,11 & 3,57 & 0,04 & 7,72 & $\mathrm{ER} / \mathrm{T}$ & 34772 \\
\hline Cenchrus echinatus L. & 4,72 & 2,86 & 0,07 & 7,65 & $\mathrm{ER} / \mathrm{T}$ & 34764 \\
\hline Chloris gayana Kunth & 0,62 & 1,43 & $<0,01$ & 2,05 & $\mathrm{ER} / \mathrm{T}$ & 34747 \\
\hline Eragrostis cilianensis (All.) Vignolo ex Janch. & 0,21 & 0,71 & $<0,01$ & 0,92 & $\mathrm{ER} / \mathrm{T}$ & 34750 \\
\hline Dactyloctenium aegyptium (L.) Willd. & 0,10 & 0,71 & $<0,01$ & 0,82 & $\mathrm{ER} / \mathrm{T}$ & 34754 \\
\hline Ichnanthus dasycoleus Tutin & - & - & - & - & $\mathrm{ER} / \mathrm{T}$ & 34996 \\
\hline Euphorbiaceae & 3,59 & 13,68 & 3,76 & 21,03 & - & - \\
\hline Cnidoscolus urens (L.) Arthur & 2,16 & 8,57 & 3,73 & 14,47 & $\mathrm{SA} / \mathrm{T}$ & 33363 \\
\hline Euphorbia hyssopifolia L. & 0,41 & 2,14 & $<0,01$ & 2,55 & $\mathrm{ER} / \mathrm{T}$ & 34503 \\
\hline Dalechampia scandens L. & 0,82 & 0,71 & 0,02 & 1,56 & $\mathrm{LVT} / \mathrm{T}$ & 34756 \\
\hline Acalypha poiretii Spreng. & 0,21 & 0,71 & $<0,01$ & 0,92 & $\mathrm{ER} / \mathrm{T}$ & 34751 \\
\hline Verbenaceae & 7,70 & 8,55 & 0,15 & 16,40 & - & - \\
\hline Lantana lucida Schauer & 7,60 & 7,14 & 0,14 & 14,89 & $\mathrm{SA} / \mathrm{T}$ & 36125 \\
\hline Priva bahiensis A.DC. & 0,10 & 0,71 & $<0,01$ & 0,82 & $\mathrm{ER} / \mathrm{T}$ & 36136 \\
\hline Bouchea sp. & - & - & - & - & $\mathrm{ER} / \mathrm{T}$ & 36124 \\
\hline Tamonea curassavica (L.) Pers. & - & - & - & - & $\mathrm{ER} / \mathrm{T}$ & 34998 \\
\hline Malvaceae & 2,57 & 10,26 & 0,25 & 13,08 & - & - \\
\hline Malvastrum coromandelianum Garcke & 1,54 & 5,00 & 0,07 & 6,61 & $\mathrm{SA} / \mathrm{T}$ & 34500 \\
\hline Sida spinosa $\mathrm{L}$ & 0,41 & 2,14 & 0,01 & 2,57 & $\mathrm{SA} / \mathrm{T}$ & 31989 \\
\hline Sida ciliaris L. & 0,31 & 2,14 & 0,10 & 2,56 & $\mathrm{ER} / \mathrm{T}$ & 34992 \\
\hline Corchorus hirtus L. & 0,21 & 0,71 & $<0,01$ & 0,93 & $\mathrm{SA} / \mathrm{T}$ & 36130 \\
\hline Pavonia cancellata (L.) Cav. & 0,10 & 0,71 & 0,05 & 0,87 & $\mathrm{ER} / \mathrm{T}$ & 35008 \\
\hline Melochia pyramidata $\mathrm{L}$. & - & - & - & - & $\mathrm{ER} / \mathrm{T}$ & 36126 \\
\hline Sida acuta Burm.f. & - & - & - & - & $\mathrm{SA} / \mathrm{T}$ & 35003 \\
\hline Maranthaceae & 3,49 & 3,42 & 4,31 & 11,23 & - & - \\
\hline Goeppertia effusa Saka \& Lombardi & 3,49 & 2,86 & 4,31 & 10,66 & $\mathrm{ER} / \mathrm{T}$ & 34995 \\
\hline Maranta noctiflora Regel \& Körn. & - & - & - & - & $\mathrm{ER} / \mathrm{T}$ & 34757 \\
\hline Acanthaceae & 1,54 & 5,98 & 0,14 & 7,66 & - & - \\
\hline Ruellia bahiensis (Nees) Morong & 1,54 & 5,00 & 0,14 & 6,68 & $\mathrm{SA} / \mathrm{T}$ & 31996 \\
\hline
\end{tabular}


Tabela 1 (continuação)

\begin{tabular}{|c|c|c|c|c|c|c|}
\hline Família/Espécie & DR & FR & DoR & VI & $\mathrm{FV} / \mathrm{S}$ & Voucher (ASE) \\
\hline Lamiaceae & 1,03 & 4,27 & 0,74 & 6,05 & - & - \\
\hline Mesosphaerum pectinatum (L.) Kuntze & 0,92 & 3,57 & 0,62 & 5,12 & $\mathrm{ER} / \mathrm{T}$ & 34487 \\
\hline Ocimum basilicum $\mathrm{L}$. & 0,10 & 0,71 & 0,12 & 0,94 & $\mathrm{ER} / \mathrm{T}$ & 36134 \\
\hline Cactaceae & 0,72 & 3,42 & 1,39 & 5,53 & - & - \\
\hline $\begin{array}{l}\text { Tacinga palmadora (Britton \& Rose) N.P. } \\
\text { Taylor \& Stuppy }\end{array}$ & 0,72 & 2,86 & 1,39 & 4,97 & $\mathrm{SA} / \mathrm{T}$ & 35005 \\
\hline $\begin{array}{l}\text { Melocactus zehntneri (Britton \& Rose) } \\
\text { Luetzelb. }\end{array}$ & - & - & - & - & $\mathrm{ER} / \mathrm{R}$ & 34495 \\
\hline Fabaceae & 1,23 & 4,27 & 0,01 & 5,52 & - & - \\
\hline Stylosanthes scabra Vogel & 1,13 & 2,86 & 0,01 & 4,00 & $\mathrm{ER} / \mathrm{T}$ & 34749 \\
\hline Chamaecrista flexuosa (L.) Greene & 0,10 & 0,71 & $<0,01$ & 0,82 & $\mathrm{SA} / \mathrm{T}$ & 34499 \\
\hline Canavalia brasiliensis Mart. ex Benth. & - & - & - & - & $\mathrm{LVT} / \mathrm{T}$ & 33366 \\
\hline Chaetocalyx scandens (L.) Urb. & - & - & - & - & $\mathrm{LVT} / \mathrm{T}$ & 34755 \\
\hline Vitaceae & 0,82 & 4,27 & 0,05 & 5,15 & - & - \\
\hline Cissus bahiensis Lombardi & 0,82 & 3,57 & 0,05 & 4,45 & $\mathrm{LVT} / \mathrm{T}$ & 34490 \\
\hline Cissus albida Cambess. & - & - & - & - & $\mathrm{LVT} / \mathrm{T}$ & 34501 \\
\hline Cissus blanchetiana Planch. & - & - & - & - & $\mathrm{LVT} / \mathrm{T}$ & 32000 \\
\hline Boraginaceae & 0,62 & 3,42 & $<0,01$ & 4,04 & - & - \\
\hline Heliotropium angiospermum Murray & 0,62 & 2,86 & $<0,01$ & 3,48 & $\mathrm{SA} / \mathrm{T}$ & 34486 \\
\hline Amaranthaceae & 0,62 & 1,71 & $<0,01$ & 2,33 & - & - \\
\hline Alternanthera tenella Colla & 0,62 & 1,43 & $<0,01$ & 2,05 & $\mathrm{SA} / \mathrm{T}$ & 32010 \\
\hline Solanaceae & 0,21 & 1,71 & 0,07 & 1,99 & - & - \\
\hline Nicandra physalodes (L.) Gaertn. & 0,21 & 1,43 & 0,07 & 1,71 & $\mathrm{ER} / \mathrm{T}$ & 34999 \\
\hline Physalis sp. & - & - & - & - & $\mathrm{ER} / \mathrm{T}$ & 36132 \\
\hline Solanum agrarium Sendtn. & - & - & - & - & $\mathrm{SA} / \mathrm{T}$ & 36140 \\
\hline Iridaceae & 0,41 & 0,85 & 0,01 & 1,28 & - & - \\
\hline Trimezia martinicensis (Jacq.) Herb. & 0,41 & 0,71 & 0,01 & 1,14 & $\mathrm{ER} / \mathrm{T}$ & 35004 \\
\hline Alstroemeriaceae & 0,21 & 0,85 & $<0,01$ & 1,06 & - & - \\
\hline $\begin{array}{l}\text { Alstroemeria longistaminea Mart. ex Schult. } \\
\text { \& Schult.f. }\end{array}$ & 0,21 & 0,71 & $<0,01$ & 0,92 & $\mathrm{ER} / \mathrm{T}$ & 31727 \\
\hline Passifloraceae & 0,10 & 0,85 & $<0,01$ & 0,96 & - & - \\
\hline Piriqueta racemosa (Jacq.) Sweet & 0,10 & 0,71 & $<0,01$ & 0,82 & $\mathrm{ER} / \mathrm{T}$ & 36131 \\
\hline Turnera chamaedrifolia Cambess. & - & - & - & - & $\mathrm{SA} / \mathrm{T}$ & 34498 \\
\hline Polygalaceae & 0,10 & 0,85 & $<0,01$ & 0,96 & - & - \\
\hline $\begin{array}{l}\text { Asemeia ovata (Poir.) J.F.B.Pastore \& } \\
\text { J.R.Abbott }\end{array}$ & 0,10 & 0,71 & $<0,01$ & 0,82 & $\mathrm{ER} / \mathrm{T}$ & 35000 \\
\hline Apiaceae & 0,10 & 0,85 & $<0,01$ & 0,96 & - & - \\
\hline Spananthe paniculata Jacq. & 0,10 & 0,71 & $<0,01$ & 0,82 & $\mathrm{ER} / \mathrm{T}$ & 36133 \\
\hline Rubiaceae & 0,10 & 0,85 & $<0,01$ & 0,96 & - & - \\
\hline $\begin{array}{l}\text { Diodella apiculata (Willd. ex Roem. \& Schult.) } \\
\text { Delprete }\end{array}$ & 0,10 & 0,71 & $<0,01$ & 0,82 & $\mathrm{ER} / \mathrm{T}$ & 34502 \\
\hline Apocynaceae & - & - & - & - & - & - \\
\hline $\begin{array}{l}\text { Mandevilla microphylla (Stadelm.) M.F. Sales } \\
\text { \& Kin.-Gouv. }\end{array}$ & - & - & - & - & $\mathrm{LVT} / \mathrm{T}$ & 34745 \\
\hline
\end{tabular}


Tabela 1 (continuação)

\begin{tabular}{|c|c|c|c|c|c|c|}
\hline Família/Espécie & DR & FR & DoR & VI & $\mathrm{FV} / \mathrm{S}$ & Voucher (ASE) \\
\hline Araceae & - & - & - & - & - & - \\
\hline Anthurium affine Schott & - & - & - & - & $\mathrm{ER} / \mathrm{R}$ & 33351 \\
\hline Philodendron leal-costae Mayo \& G.M.Barroso & - & - & - & - & $\mathrm{ER} / \mathrm{T}$ & 33347 \\
\hline Caprifoliaceae & - & - & - & - & - & - \\
\hline Valeriana scandens L. & - & - & - & - & $\mathrm{LVT} / \mathrm{T}$ & 32013 \\
\hline Commelinaceae & - & - & - & - & - & - \\
\hline Commelina erecta $\mathrm{L}$. & - & - & - & - & $\mathrm{ER} / \mathrm{R}$ & 34758 \\
\hline Convolvulaceae & - & - & - & - & - & - \\
\hline Evolvulus glomeratus Nees \& Mart. & - & - & - & - & $\mathrm{ER} / \mathrm{T}$ & 34480 \\
\hline Ipomoea brasiliana (Choisy) Meisn. & - & - & - & - & $\mathrm{LVT} / \mathrm{T}$ & 34997 \\
\hline Ipomoea hederifolia $\mathrm{L}$. & - & - & - & - & $\mathrm{LVT} / \mathrm{T}$ & 34491 \\
\hline Ipomoea $\mathrm{sp}$. & - & - & - & - & $\mathrm{LVT} / \mathrm{T}$ & 34746 \\
\hline Cucurbitaceae & - & - & - & - & - & - \\
\hline Cucumis dipsaceus Ehrenb. & - & - & - & - & $\mathrm{LVT} / \mathrm{T}$ & 36137 \\
\hline Cyperaceae & - & - & - & - & - & - \\
\hline Cyperus squarrosus L. & - & - & - & - & $\mathrm{ER} / \mathrm{T}$ & 34766 \\
\hline Dioscoreaceae & - & - & - & - & - & - \\
\hline Dioscorea ovata Vell. & - & - & - & - & $\mathrm{LVT} / \mathrm{T}$ & 32001 \\
\hline Malpighiaceae & - & - & & - & - & - \\
\hline Galphimia brasiliensis (L.) A.Juss. & - & - & - & - & $\mathrm{SA} / \mathrm{T}$ & 36127 \\
\hline Stigmaphyllon auriculatum (Cav.) A.Juss. & - & - & - & - & $\mathrm{LVT} / \mathrm{T}$ & 34492 \\
\hline Orchidaceae & - & - & - & - & - & - \\
\hline Oeceoclades maculata (Lindl.) Lindl. & - & - & - & - & $\mathrm{ER} / \mathrm{T}$ & 31999 \\
\hline $\begin{array}{l}\text { Trichocentrum cebolleta (Sw.) M.W.Chase \& } \\
\text { N.H.Williams }\end{array}$ & - & - & - & - & $\mathrm{ER} / \mathrm{E}$ & 33321 \\
\hline Vanilla palmarum (Salzm. ex Lindl.) Lindl & - & - & - & - & $\mathrm{ER} / \mathrm{HE}$ & 35018 \\
\hline
\end{tabular}

corresponde a apenas $0,0008 \%$ da área total desta vegetação (IBGE 2004). Em relação a Sergipe, esses valores correspondem a $12 \%, 16 \%$ e $31 \%$ de espécies, gêneros e famílias, respectivamente, dos números totais para a vegetação de Caatinga deste Estado (Flora do Brasil 2020 em construção), demonstrando que o fragmento estudado abriga uma grande parcela da biodiversidade herbácea.

A maior parte das espécies encontradas (87\%) possui registro de ocorrência em outros domínios fitogeográficos, principalmente à Mata Atlântica (76\% das espécies) e ao Cerrado ( $71 \%$ das espécies). Porém, nove (13\% do total) das espécies encontradas são endêmicas da Caatinga (Giulietti et al. 2002, Flora do Brasil 2020 em construção). A composição florística observada na área de estudo permite-nos fazer inferências sobre o efeito da antropização na região, uma vez que 31 espécies (ou 43\%) são típicas de áreas antropizadas da Caatinga (Flora do Brasil $2020 \mathrm{em}$ construção) e uma espécie, Cenchrus echinatus L., é classificada como exótica invasora (I3N Brasil/ Instituto Hórus 2016). C. echinatus é uma espécie agressiva com potencial alelopático, podendo inibir a germinação e o desenvolvimento de espécies nativas (Araujo et al. 2013, I3N Brasil/Instituto Hórus 2016). A existência de espécies típicas de áreas antropizadas e de uma espécie exótica invasora, um reflexo do estado de conservação da área, gera preocupação quanto à manutenção da biodiversidade herbácea no fragmento estudado.

A riqueza observada foi considerada intermediária, sendo maior que $61 \%$ da riqueza encontrada em outras áreas de Caatinga, que variaram de 18 a 300 espécies (tabela 2). Entretanto, é fundamental ressaltar que existem diferenças metodológicas entre os estudos (por exemplo: área e época de amostragem, assim como esforço de coleta), além de aspectos climáticos locais, como a precipitação anual (tabela 2), o que dificulta 
Tabela 2. Riqueza da flora herbácea, método de amostragem e taxa de precipitação anual $(\mathrm{mm})$ registrados por estudos realizados em áreas de Caatinga. *: incluíram espécies localizadas próximas as parcelas amostradas.

Table 2. Richness of the herbaceous flora, sampling method and rate of annual rainfall $(\mathrm{mm})$ recorded by previous studies carried out in areas of Caatinga *: included species located near the sampled plots.

\begin{tabular}{|c|c|c|c|c|}
\hline Autor (ano) & Estado & Métodos & Riqueza & Precipitação anual (mm) \\
\hline Sizenando-Filho et al. (2007) & PB & Parcelas & 18 & 625 \\
\hline Benevides et al. (2007) & $\mathrm{RN}$ & Parcelas & 37 & 650 \\
\hline Andrade et al. (2009) & $\mathrm{PB}$ & Parcelas & 40 & 400 \\
\hline Pessoa et al. (2004) & $\mathrm{PE}$ & Caminhadas & 54 & 511 \\
\hline Araujo et al. (2005) & $\mathrm{PE}$ & Parcelas* & 62 & 694 \\
\hline Pereira et al. (2008) & $\mathrm{PE}$ & Parcelas* & 62 & 694 \\
\hline Rodal et al. (2005) & $\mathrm{PE}$ & Parcelas & 64 & 511 \\
\hline Reis et al. (2006) & $\mathrm{PE}$ & Parcelas* & 71 & 710 \\
\hline Costa et al. (2007) & $\mathrm{CE}$ & Caminhadas & 77 & 732,8 \\
\hline Este estudo & SE & Caminhadas e parcelas & 80 & 780 \\
\hline Silva et al. (2012) & PB & Caminhadas & 84 & 800 \\
\hline Silva et al. (2009) & $\mathrm{PE}$ & Parcelas* & 95 & 435 \\
\hline Silva et al. (2013a) & $\mathrm{PE}$ & Parcelas* & 95 & 435 \\
\hline Santos (2010) & $\mathrm{PE}$ & Parcelas* & 123 & 694 \\
\hline Oliveira et al. (2013) & SE & Caminhadas e parcelas & 153 & 548,9 \\
\hline Queiroz (2006) & $\mathrm{RN}$ & Caminhadas & 300 & 497 \\
\hline
\end{tabular}

uma avaliação sobre os efeitos da antropização na riqueza encontrada a partir de comparação com a literatura. Uma compilação realizada por Feitoza (2013) mostrou que a antropização afeta negativamente a riqueza da flora herbácea de Caatinga (por exemplo, Maracajá \& Benevides 2006, Sizenando-Filho et al. 2007, Silva 2011). Entretanto, é preciso analisar o tipo de perturbação, a magnitude e o tempo, pois alguns grupos de ervas são muito comuns em áreas abertas, podendo haver um aumento de riqueza nessas áreas (Alves 2009, Feitoza 2013).

Quando avaliada a relação entre precipitação anual e a riqueza nas áreas de Caatinga, percebe-se que este fator ambiental não explica a variação de riqueza encontrada $\left(r_{\mathrm{s}}=-0,01 ; \mathrm{p}=0,96\right)$. Este resultado está em acordo com Oliveira et al. (2013), os quais apontam que a precipitação é menos determinante na variação da riqueza de herbáceas na Caatinga que os métodos de amostragem dos levantamentos. Em dois outros estudos realizados com a flora herbácea de Caatinga, também não foi observado um incremento da riqueza com aumento da precipitação entre dois anos consecutivos (Reis et al. 2006, Feitoza 2013). É possível que a sazonalidade pluvial seja mais importante na variação do número de espécies herbáceas da Caatinga do que o volume total de precipitação (por exemplo, Lima et al. 2012, Oliveira et al. 2013). Além disso, outros fatores como o tipo de substrato (por exemplo, cristalino e sedimentar) e de micro-habitat (por exemplo, rochoso, plano e ciliar) também contribuem por diferenças na riqueza da flora herbácea de Caatinga (Araujo et al. 2005, Reis et al. 2006, Pereira et al. 2008, Silva et al. 2013a).

O baixo número de famílias deste estudo pode estar associado a um processo de simplificação biótica resultante da antropização observada (por exemplo, Vieira \& Gardner 2012, Mallmann et al. 2015), contribuindo para a existência de muitas espécies em uma única família, ou seja, táxons filogeneticamente mais próximos (Judd et al. 2009, Souza \& Lorenzi 2012). O número de famílias encontrado neste estudo foi superior apenas a $16 \%$ dos estudos analisados na Caatinga, que apresentam entre 24 e 64 famílias (Pessoa et al. 2004, Araujo et al. 2005, Queiroz 2006, Reis et al. 2006, Costa et al. 2007, Pereira et al. 2008, Andrade et al. 2009, Silva et al. 2009, Silva et al. 2012, Santos et al. 2013, Silva et al. 2013a, Oliveira et al. 2013).

As famílias com o maior número de espécies (figura 2) foram Asteraceae, Malvaceae e Poaceae (sete espécies cada) e Bromeliaceae (seis espécies). As famílias com apenas uma espécie correspondem a $47 \%$ do total de famílias e $20 \%$ do total de espécies. 


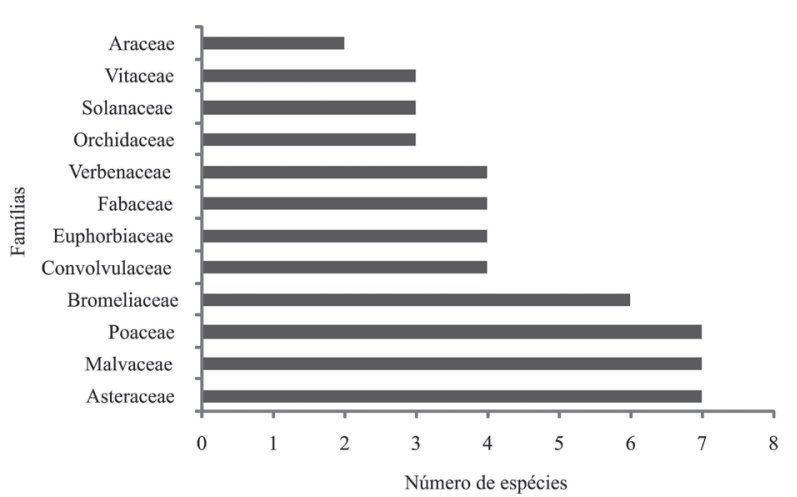

Figura 2. Famílias com maior número de espécies para o fragmento de Caatinga no município de Poço Verde, centro-sul de Sergipe, Brasil.

Figure 2. Families with the largest number of species in the Caatinga fragment, municipality of Poço Verde, south-central region of Sergipe State, Brazil.

As famílias Asteraceae, Malvaceae e Poaceae são comumente citadas entre as três primeiras famílias mais importantes do estrato herbáceo em diferentes áreas de Caatinga (Pessoa et al. 2004, Araujo et al. 2005, Rodal et al. 2005, Reis et al. 2006, Costa et al. 2007, Silva et al. 2009, Silva 2011, Silva et al. 2012, Feitoza 2013, Oliveira et al. 2013, Costa et al. 2016). Destas três famílias, Poaceae é a que possui o maior número de espécies registradas para a Caatinga (346), seguida de Asteraceae, com 291 espécies e Malvaceae, com 161 espécies (Flora do Brasil 2020 em construção). Com exceção de Poaceae, cujos indivíduos ocuparam com maior frequência as áreas antropizadas do fragmento, as famílias Asteraceae e Malvaceae, apresentaram seus indivíduos com distribuição para um maior número de micro-habitats, incluindo áreas de bordas e trilhas e de vegetação arbustivo-arbórea mais fechada. Dentre estas três famílias, as espécies de Poaceae podem ter se beneficiado da presença de áreas abertas oriundas da antropização do fragmento, ambientes estes, ideais para seu desenvolvimento (Souza \& Lorenzi 2012).

Com relação à similaridade florística, observou-se a formação de dois grupos distintos, um formado pelos estudos realizados nos Estados de Sergipe e Pernambuco e outro formado pelos estudos realizados nos Estados da Paraíba e Rio Grande do Norte (figura 3). A área de estudo (SE2) apresentou maior similaridade florística com SE1, e maior dissimilaridade com PB1, PB2, RN/PB e RN. Todos os valores de similaridade florística foram baixos, ou seja, inferiores a 0,50, compondo comunidades vegetais distintas (Lima et al. 2012).

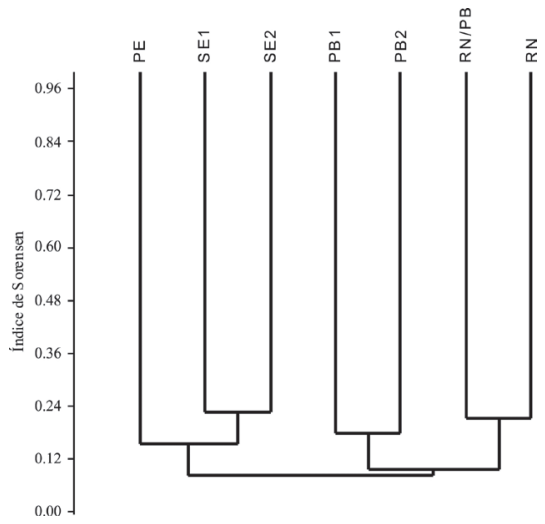

Figura 3. Dendograma gerado a partir de uma matriz binária (presença/ausência) da distribuição das espécies registradas nas áreas de Caatinga analisadas utilizando média aritmética não ponderada por grupo (UPGMA) e o coeficiente de Sørensen. SE1: Oliveira et al. (2013); SE2: este estudo; PE: Reis et al. (2006); PB1: Andrade et al. (2009); PB2: Silva et al. (2012); RN/PB: Sizenando-Filho et al. (2007); RN: Benevides et al. (2007).

Figure 3. Dendrogram generated from a binary matrix (presence/ absence) of the distribution of species recorded in the Caatinga areas analyzed using the unweighted arithmetic average per group (UPGMA) and the Sørensen index. SE1: Oliveira et al. (2013); SE2: this study; PE: Reis et al. (2006); PB1: Andrade et al. (2009); PB2: Silva et al. (2012); RN/PB: Sizenando-Filho et al. (2007); $\mathrm{RN}$ : Benevides et al. (2007).

Não foi observada uma correlação significativa entre a similaridade e a distância geográfica $(\mathrm{r}=-0,28$; $\mathrm{p}=0,89)$. Com exceção das áreas de Sergipe (SE1 e SE2), da Paraíba (PB1 e PB2) e da divisa Paraíba/ Rio Grande do Norte e Rio Grande do Norte (RN/ $\mathrm{PB}$ e $\mathrm{RN}$ ), áreas próximas apresentaram maior dissimilaridade florística, conforme observado entre PE e PB1 $\left(I_{s}=0,06\right), R N / P B$ e PB1 $\left(I_{s}=0\right)$ e PB1 e RN $\left(I_{s}=0,06\right)$. Observou-se ainda que o estudo realizado em Pernambuco (PE) apresentou maior similaridade com as áreas de Sergipe - SE1 $\left(I_{s}=0,20\right)$ e SE2 $\left(I_{s}=0,10\right)$ - do que com as áreas de menor distância geográfica na Paraíba e no Rio Grande do Norte - PB1 $\left(I_{s}=0,06\right)$ e RN $\left(I_{s}=0,06\right)$ - cuja similaridade foi quase nula.

Diante da falta de influência da distância geográfica na similaridade florística entre as áreas analisadas, atribui-se a diferenças nos fatores ambientais, como causa do padrão de agrupamento observado, corroborando com alguns estudos na Caatinga (Cardoso \& Queiroz 2007, Lima et al. 2012). É provável que um conjunto de características peculiares (por exemplo, altitude, tipologia de solos, pluviometria), seja responsável pela similaridade ou dissimilaridade entre as áreas analisadas (Lacerda et al. 2005, Calixto-Jr \& Drumond 2014). 
Por exemplo, as áreas $\mathrm{RN}$ e RN/PB possuem valores muito semelhantes de precipitação, temperatura, altitude e níveis de antropização (Benevides et al. 2007, Sizenando-Filho et al. 2007). Com relação às áreas de Sergipe (SE1 e SE2), estas compartilham solos de textura semelhante, estão inseridos sobre o embasamento cristalino e apresentam pequena diferença altimétrica (Oliveira et al. 2013, Oliveira 2016).

Com relação à estrutura, na área das subparcelas foi verificada uma densidade de 32,46 ind $\mathrm{m}^{2}$ e uma área basal de $41,6 \mathrm{~m}^{2} \mathrm{ha}^{-1}$. Estes números foram superiores aos valores de densidade $\left(20,84\right.$ ind $\left.\mathrm{m}^{2}\right)$ e área basal $\left(26,92 \mathrm{~m}^{2} \mathrm{ha}^{-1}\right)$ observados em uma área de Caatinga em Sergipe (Oliveira et al. 2013). Porém, inferiores aos valores encontrados de densidade $(38,5$, 738 e 1.398 ind $\left.\mathrm{m}^{2}\right)$ e área basal $\left(85,86 \mathrm{~m}^{2} \mathrm{ha}^{-1}\right)$ para áreas de Caatinga em Pernambuco e na Paraíba (Reis et al. 2006, Andrade et al. 2009, Silva et al. 2013a). De forma geral, estas diferenças são explicadas por características ambientais distintas. Por exemplo, na vegetação herbácea de Caatinga tem sido constatado que a densidade e a área basal aumentam com a precipitação e a antropização (Santos et al. 2006,
Benevides et al.2007, Andrade et al. 2009, Silva 2011, Oliveira et al. 2013), tendência esta, observada entre os estudos comparados. Fatores como precipitação e estado de conservação possuem um papel importante nas variações estruturais da flora herbácea de Caatinga (por exemplo, Santos et al. 2006, Benevides et al. 2007, Sizenando-Filho et al. 2007, Andrade et al. 2009, Lima et al. 2012, Feitoza 2013, Oliveira et al. 2013).

Os valores encontrados dos índices de diversidade Shannon-Wiener (H') e da equabilidade de Pielou (J) foram considerados intermediários, dentro da faixa esperada para áreas antropizadas de Caatinga (tabela 3). Apesar disso, os valores de H' e J encontrados foram superiores a dois valores de áreas conservadas de Caatinga e localizados no limite entre os valores de áreas antropizadas e conservadas (tabela 3). Apesar da existência de perturbação no fragmento estudado, esta antropização é espacialmente variada (por exemplo, observada nas subparcelas próximas a trilhas), com a existência de trechos em bom estado de conservação.

As espécies de maior VI foram Aechmea aquilega (Salisb.) Griseb., Ageratum conyzoides L. e Paspalum

Tabela 3. Diversidade Shannon-Wiener (H') e equabilidade de Pielou (J) do estrato herbáceo em áreas de Caatinga antropizadas e conservadas. *: levantamento realizado em áreas com estado de conservação distinto. Obs.: as referências de áreas como semi-conservada, intermediária e inicial foram consideradas como antropizadas.

Table 3. Shannon-Wiener diversity $\left(\mathrm{H}^{\prime}\right)$ and Pielou evenness $(\mathrm{J})$ of the herbaceous flora in disturbed and conserved areas of Caatinga *: survey performed in areas with different conservation status. Obs.: studies considering areas as semi-preserved, intermediate and initial were considered here as disturbed.

\begin{tabular}{|c|c|c|c|c|}
\hline Autor (ano) & Estado & Estado de conservação & $\mathrm{H}^{\prime}\left(\right.$ nats.ind $\left.^{-1}\right)$ & $\mathrm{J}$ \\
\hline Miranda et al. (2007)* & RN & Conservado & 0,88 & - \\
\hline Sizenando-Filho et al. (2007) & PB & Antropizado & $1,49-1,99$ & \\
\hline Miranda et al. (2007)* & $\mathrm{RN}$ & Antropizado & 1,77 & - \\
\hline Santos $(2010)^{*}$ & PE & Antropizado & $1,91-1,94$ & - \\
\hline Silva $(2011)^{*}$ & PB & Antropizado & $2,03-2,71$ & $0,51-0,67$ \\
\hline Andrade et al. (2009)* & $\mathrm{PB}$ & Antropizado & $2,26-3,06$ & - \\
\hline Santos et al. (2006)* & $\mathrm{RN}$ & Conservado & 2,39 & - \\
\hline Benevides et al. (2007) & $\mathrm{RN}$ & Antropizado & $2,40-2,45$ & - \\
\hline Este estudo & SE & Antropizado & 2,42 & 0,62 \\
\hline Santos et al. (2006)* & $\mathrm{RN}$ & Antropizado & 2,44 & - \\
\hline Reis et al. (2006) & $\mathrm{PE}$ & Conservado & $2,66-3,01$ & $0,71-0,77$ \\
\hline Rodal et al. (2005) & $\mathrm{PE}$ & Conservado & $2,80-3,19$ & - \\
\hline Silva et al. (2013) & $\mathrm{PE}$ & Conservado & $2,96-2,89$ & - \\
\hline Andrade et al. (2009)* & PB & Conservado & $3,25-3,32$ & - \\
\hline Silva $(2011)^{*}$ & PB & Conservado & 3,26 & 0,8 \\
\hline
\end{tabular}


fimbriatum Kunth (tabela 1), com cerca de 47\% do total dos VIs e apresentado-se em teoria como as espécies de maior sucesso em explorar os recursos da área. Em Sergipe, estas espécies possuem registro em boa parte dos estudos existentes na Caatinga, tanto naqueles realizados especificamente com o estrato herbáceo (Oliveira et al. 2013), como em todos os estratos (Nogueira-Jr 2011, Machado et al. 2012, Ferreira et al. 2013, Silva et al. 2013b).

O diâmetro elevado de Aechmea aquilega (Salisb.) Griseb. foi o fator influenciador para que esta espécie tivesse o maior VI neste estudo (tabela 1). Quando presente, indivíduos desta espécie ocupavam com frequência toda a área da subparcela, o que confirma a observação feita anteriormente de que indivíduos da família Bromeliaceae dominam o sub-bosque da área estudada (Anholetto-Jr 2013). A. aquilega pode ocorrer como epífita, rupícola ou terrícola, principalmente em áreas de Caatinga, mas também existem registros dessa espécie na Amazônia, Mata Atlântica e no Cerrado (Flora do Brasil 2020 em construção).

Ageratum conyzoides L. foi também à espécie de maior densidade relativa (38\%) (tabela 1), sendo abundante nas subparcelas com fitofisionomias abertas e/ou aquelas próximas às bordas de trilhas. O seu elevado valor de frequência relativa $(7,14 \%)$ e principalmente densidade relativa contribuíram para seu elevado VI. Esta espécie possui substrato terrícola e ocorrência para todos os estados e domínios fitogeográficos do Brasil, incluindo áreas antropizadas (Flora do Brasil 2020 em construção).

Encontrada principalmente nas subparcelas mais próximas das áreas de pastagem ou de clareiras oriundas da antropização, Paspalum fimbriatum Kunth obteve a segunda maior densidade relativa $(13,6 \%)$ e o segundo maior valor de frequência relativa $(7,14 \%)$, igualando-se com outras duas espécies (Ageratum conyzoides L. e Lantana lucida Schauer). Esta espécie anual possui substrato terrícola e ocorrência restrita para áreas de Caatinga e Cerrado, incluindo locais antropizados (Maciel 2013, Flora do Brasil 2020 em construção). Em Sergipe, esta espécie ocorre em áreas de Caatinga com solos úmidos, arenosos e pedregosos (Maciel 2013).

É provável que atributos ecológicos tenham sido responsáveis pelo elevado VI destas três espécies na área estudada. Por exemplo, a broméliatanque Aechmea aquilega, é uma das espécies de Bromeliaceae que armazena um maior volume de água. A partir de absorção foliar por meio de tricomas, pode obter umidade e nutrientes, garantindo a sua sobrevivência em períodos secos (Hefler \& Faustioni 2004, Bonet \& Queiroz 2006, Cogliatti-Carvalho et al. 2010, Dias et al. 2014).

Além de Aechmea aquilega (Salisb.) Griseb., Bromelia laciniosa Mart. ex Schult. \& Schult.f., a quarta espécie de maior VI (tabela 1), também contribuiu para que Bromeliaceae fosse a família de maior VI (tabela 1). Além deste estudo, a família Bromeliaceae, em consequência aos altos VIs de Bromelia laciniosa ex Schult. \& Schult.f. e Neoglaziovia variegata (Arruda) Mez, também se destacou em uma área de Caatinga de Sergipe (Oliveira et al. 2013). Nos solos de Caatinga as espécies dessa família são muito comuns, provavelmente por sua grande resistência ao estresse hídrico (Andrade-Lima 1981, Oliveira et al. 2013).

Para os locais antropizados do fragmento estudado, observou-se que a composição florística e a estrutura da vegetação herbácea eram distintas das áreas mais conservadas. Essa observação, somado ao fato da presença de espécies exóticas invasoras e elevado número de plantas típicas de áreas antropizadas, a baixa riqueza de famílias e os índices de diversidade e equabilidade, cujos valores foram associados a áreas perturbadas podem sugerir que a antropização observada no fragmento modificou a composição e estrutura da vegetação herbácea estudada, razão pela qual, recomendam-se ações voltadas para a conservação deste estrato. Além disso, sugere-se que a sazonalidade da precipitação seja mais importante que o seu volume na determinação de variações na riqueza da flora herbácea de Caatinga. As diferenças estruturais entre os estudos analisados foram atribuídas a peculiaridades ambientais, bem como as diferenças de similaridade florística entre as áreas de Caatinga. Finalmente, os atributos ecológicos foram responsáveis por diferenças estruturais entre as espécies estudadas. Os resultados encontrados reforçam a necessidade de inclusão da vegetação herbácea nas estratégias de conservação da Caatinga. Além disso, este trabalho amplia o conhecimento sobre o estrato herbáceo desta vegetação em Sergipe.

\section{Agradecimentos}

À Coordenação de Aperfeiçoamento de Pessoal de Nível Superior (CAPES) pela concessão de bolsa de mestrado ao primeiro autor; à Universidade Federal de Sergipe pela concessão de transporte; aos estagiários do Herbário ASE pela ajuda nos trabalhos de campo. 


\section{Literatura citada}

Álvares, C.A., Stape, J.L., Sentelhas, P.C., Gonçalves J.L.M. \& Sparovek, G. 2014. Köppen's climate classification map for Brazil. Meteorologische Zeitschrift 22: 711-728.

Alves, J.A.A.A. 2009. Caatinga no Cariri Paraibano. Geonomos 17: 19-25.

Andrade-Lima, D. 1981. The Caatingas dominium. Revista Brasileira de Botânica 4: 149-153.

Andrade, M.V.M., Andrade, A.P., Silva, D.S., Bruno, R.L.A. \& Guedes, D.S. 2009. Levantamento florístico e estrutura fitossociológica do estrato herbáceo e subarbustivo em áreas de Caatinga no Cariri paraibano. Revista Caatinga 22: 229-237.

Anholetto-Jr, C.R. 2013. Dendroecologia e composição isotópica $\left(\delta^{13} \mathrm{C}\right)$ dos anéis de crescimento de árvores de Cedrela odorata, Meliaceae, na Caatinga e Mata Attântica do estado de Sergipe, Brasil. Dissertação de Mestrado, Universidade de São Paulo, Piracicaba.

APG IV. 2016. An update of the Angiosperm Phylogeny Group classification for the orders and families of flowering plants: APG IV. Botanical Journal of the Linnean Society 181: 1-20.

Araújo, E.L., Silva, K.A., Ferraz, E.M.N., Sampaio, E.V.S.B \& Silva, S.I. 2005. Diversidade de herbáceas em microhabitats rochoso, plano e ciliar em uma área de Caatinga, Caruaru, PE, Brasil. Acta Botanica Brasilica 19: 285-294.

Araújo, K.C.T., Fabricante, J.R., Castro, R.A., Furtado, M.D.G. \& Siqueira-Filho, J.A. 2013. Cenchrus echinatus L. In: J.R. Fabricante (org.). Plantas exóticas e exóticas invasoras da Caatinga. Bookess, Florianópolis, pp. 20-27.

Benevides, D.S., Maracajá, P.B., Sizenando-Filho, F.A., Guerra, A.M.N.M. \& Pereira, T.F.C. 2007. Estudo da flora herbácea da Caatinga no município de Caraúbas no estado do Rio Grande do Norte. Revista Verde 2: 33-44.

Bonnet, A. \& Queiroz, M.H. 2006. Estratificação vertical de bromélias epifíticas em diferentes estádios sucessionais da Floresta Ombrófila Densa, Ilha de Santa Catarina, Santa Catarina, Brasil. Revista Brasileira de Botânica 29: 217-228.

Calixto-Jr., J.T. \& Drumond, M.A. 2014. Estudo comparativo da estrutura fitossociológica de dois fragmentos de Caatinga em níveis diferentes de conservação. Pesquisa Florestal Brasileira 34: 345-355.

Cardoso, D.B.O.S. \& Queiroz, L.P. 2007. Diversidade de Leguminosae nas caatingas de Tucano, BA: implicações para a fitogeografia do semi-árido do Nordeste do Brasil. Rodriguésia 58: 379-371.

Citadini-Zanette, V., Pereira, J.L., Jarenkow, J.A., Klein, A.S. \& Santos, R.S. 2011. Estrutura da sinúsia herbácea em Floresta Ombrófila Mista no Parque Nacional de Aparados da Serra, sul do Brasil. Revista Brasileira de Biociências 9: 56-63.
Cogliatti-Carvalho, L., Rocha-Pessôa, T.C., NunesFreitas, A.F. \& Rocha, C.F.D. 2010. Volume de água armazenado no tanque de bromélias em restingas da costa brasileira. Acta Botanica Brasilica 24: 84-95.

Costa, F.R.C. 2004. Structure and composition of the ground-herb community in a terra-firme Central Amazonian forest. Acta Amazonica 34: 53-59.

Costa, F.R.C., Magnusson, W.E. \& Luizão, R.C. 2005. Mesoscale distribution patterns of Amazonian understorey herbs in relation to topography, soil and watersheds. Journal of Ecology 93: 863-878.

Costa, R.C., Araújo, F.S. \& Lima-Verde, L.W. 2007. Flora and life-form spectrum in an area of deciduous thorn woodland (Caatinga) in northeastern, Brazil. Journal of Arid Environments 68: 237-247.

Costa, D.F.S., Sena, V.R.R., Oliveira, A.M. \& Rocha, R.M. 2016. Análise da diversidade da vegetação herbácea em reservatório no semiárido brasileiro (açude Itans - RN). Biotemas 29: 25-36.

Dias, M.L., Prezoto, F., Abreu, P.F. \& Menini-Neto, L. 2014. Bromélias e suas principais interações com a fauna. CES Revista 28: 3-16.

ESRI - Environmental Systems Research Institute. 2008. ArcGIS. Version 9.3. New York.

Feitoza, M.O.M. 2013. Variação interanual do componente herbáceo em áreas de Caatinga preservada e manejada no sertão pernambucano. Tese de Doutorado. Universidade Federal Rural de Pernambuco, Recife.

Ferreira, E.V.R. 2011. Composição florística, estrutura da vegetação e síndrome de dispersão de sementes de um remanescente de Caatinga em Poço Verde, Sergipe. Dissertação de Mestrado. Universidade Federal de Sergipe, São Cristóvão.

Ferreira, E.V.R., Prata, A.P.N. \& Mello, A.A. 2013. Floristic list from a Caatinga remnant in Poço Verde, Sergipe, Brazil. Check List 9: 1354-1360.

Flora do Brasil 2020 em Construção. Disponível em http://floradobrasil.jbrj.gov.br/ (acesso em 15-IV-2016).

Giulietti, A.M., Harley, L.M., Queiroz, L.P., Barbosa, M.R.V., Bocage-Neta, A.L. \& Figueiredo, M.A. 2002. Plantas endêmicas da Caatinga. In: E.V.S.B. Sampaio, A.M. Giulietti, J. Virgínio C.F.L. \& Gamarra-Rojas (Orgs.). Vegetação e flora das Caatingas. APNE/CNIP, Recife, pp. 103-115.

Hammer, Ø., Harper, D.A.T. \& Ryan, P.D. 2013. PAST - Palaeontological statistics. Disponível em http://folk. uio.no/ohammer/past/ (acesso em 15-X-2013).

Hefler, S.M. \& Faustioni, P. 2004. Levantamento florístico de epífitos vasculares do Bosque São Cristóvão Curitiba - Paraná - Brasil. Revista Estudos de Biologia 26: 11-19.

I3N Brasil/Instituto Hórus. 2016. Base de dados nacional de espécies exóticas invasoras. Disponível em http:// i3n.institutohorus.org.br/www (acesso em 10-XI2016). 
IBGE - Instituto Brasileiro de Geografia e Estatística. 2004. Mapa de Biomas do Brasil, primeira aproximação. IBGE, Rio de Janeiro. Disponível em http://www.ibge.gov.br/home/presidencia/ noticias/21052004biomashtml.shtm (acesso em 20-XII-2015).

Inácio, C.D. \& Jarenkow, J.A. 2008. Relações entre a estrutura da sinúsia herbácea terrícola e a cobertura do dossel em floresta estacional no Sul do Brasil. Revista Brasileira de Botânica 31: 41-51.

Judd, W.S., Campbell, C.S., Kellogg, E.A., Stevens, P.F. \& Donoghu, M.J. 2009. Sistemática Vegetal: Um Enfoque Filogenético. Artmed, Porto Alegre.

Lacerda, A.V., Nordi, N., Barbosa, F.M. \& Watanabe, T. 2005. Levantamento florístico do componente arbustivoarbóreo da vegetação ciliar na bacia do rio Taperoá, PB, Brasil. Acta Botanica Brasilica 19: 647-656.

Lima, R.A.F. \& Gandolfi, S. 2009. Structure of the herb stratum under different light regimes in the Submontane Atlantic Rain Forest. Brazilian Journal of Biology 69: 289-296.

Lima, E.N. 2011. Influência do componente herbáceo da Caatinga na regeneração natural de plantas lenhosas em uma área de vegetação preservada e uma área de agricultura abandonada. Tese de Doutorado. Universidade Federal Rural de Pernambuco, Recife.

Lima, B.G., Coelho, M.F.B. \& Oliveira, O.F. 2012. Caracterização florística de duas áreas de caatinga na região centro-sul do Ceará, Brasil. Bioscience Journal 28: 277-296.

Machado, W.J., Prata, A.P.N. \& MELLO, A.A. 2012. Floristic composition in areas of Caatinga and Brejo de Altitude in Sergipe state, Brazil. Check List 8: 1089-1101.

Maciel, J.R. 2013. Poaceae I. In: A.P. Prata, M.C.E. Amaral, M.C.V. Farias \& M.V. Alves (orgs.). Flora de Sergipe, v. 1. Gráfica e Editora Triunfo, Aracaju, pp. 510-521.

Mallmann, I.T., Silva, L.V. \& Schmitt, J.L. 2016. Estrutura comunitária de samambaias em mata ciliar: avaliação em gradiente de antropização. Ambiente \& Água 11: 110-124.

Maracajá, P.B \& Benevides, D.N. 2006. Estudo da flora herbácea da Caatinga no município de Caraúbas no Estado do Rio Grande do Norte. Revista de Biologia e Ciências da Terra 6: 165-175.

Miranda, M.A.S., Maracajá, P.B., Sousa, D.D., Lima, R.B., Melo, S.B. \& Amorim, S.B. 2007. A flora herbácea na Flona de Açú-RN. Agropecuária Científica no Semi-Árido 3: 31-43.

Mori, S.A., Silva, L.A.M., Lisboa, G. \& Coradin, L. 1985. Manual de manejo do herbário fanerogâmico. Centro de Pesquisas do Cacau, Ilhéus.

Mueller-Dombois, D. \& Ellenberg, H. 1974. Aims and methods of vegetation ecology. John Wiley \& Sons, New York.
Nogueira-Jr, F.C. 2011. Estrutura e composição de uma vegetação ripária, relações dendrocronológicas e climáticas, na Serra dos Macacos em Tobias Barreto, Sergipe - Brasil. Dissertação de Mestrado. Universidade Federal de Sergipe, São Cristóvão.

Oliveira, E.V.S. 2016. Dinâmica temporal e aspectos da vegetação em uma comunidade de Caatinga. Dissertação de Mestrado. Universidade Federal de Sergipe, São Cristóvão.

Oliveira, D.G., Prata, A.P. \& Ferreira, R.A. 2013. Herbáceas da Caatinga: composição florística, fitossociologia e estratégias de sobrevivência em uma comunidade vegetal. Revista Brasileira de Ciências Agrárias 8: 623-633.

Pereira, A.P.C. \& Secorun, A.C. 2007. Estrutura e adaptação das plântulas. UNINGÁ 12: 161-169.

Pereira, R.M.A., Araújo-Filho, J.A., Lima, R.V., Paulino, F.D.G., Lima, A.O.M. \& Araújo, Z.B. 1989. Estudos fenológicos de algumas espécies lenhosas e herbáceas da Caatinga. Ciência Agronômica 20: 11-20.

Pereira, V.F., Araújo, E.L., Silva, K.S., Lima, E.M., Andrade, J.R. \& Pimentel, R.M. M. 2008. Associações entre espécies herbáceas em uma área de Caatinga de Pernambuco. Revista de Geografia 25: 6-23.

Pessoa, L.M., Rodal, M.J.N., Silva, A.C.B.L. \& Costa, K.C.C. 2004. Levantamento da flora herbácea de um trecho de Caatinga, RPPN Maurício Dantas, Betânia/ Floresta, Pernambuco. Revista Nordestina de Biologia 18: 27-53.

Prado, D.E. 2008. As Caatingas da América do Sul. In: R.I. Leal, M. Tabarelli \& J.M.C. Silva (orgs.). Ecologia e Conservação da Caatinga. Universidade Federal de Pernambuco, Recife, pp. 3-73.

Prata, A.P.N., Amaral, M.C.E., Farias M.C.V. \& Alves, M.V. 2013. Flora de Sergipe, v. 1. Gráfica e Editora Triunfo, Aracaju.

Prata, A.P.N., Farias, M.C.V. \& Landim, M.F. 2015. Flora de Sergipe, v. 2. Editora Criação, Aracaju.

Queiroz, L.P. 2009. Leguminosas da Caatinga. Universidade Estadual de Feira de Santana, Feira de Santana.

Queiroz, R.T. 2006. Diversidade florística do componente herbáceo na Estação Ecológica do Seridó, Serra Negra do Norte RN, Brasil. Dissertação de Mestrado. Universidade Federal do Rio Grande do Norte, Natal.

Ramalho, C.I., Andrade, A.P., Félix, L.P., Lacerda, A.V. \& Maracajá, P.B. 2009. Flora arbóreo-arbustiva em áreas de caatinga no semiárido baiano, Brasil. Revista Caatinga 22: 182-190.

Reis, A.M.S., Araújo, E.L., Ferraz, E.B.M. \& Moura, A.N. 2006. Inter-annual variations in the floristic and population structure of herbaceous community of "Caatinga" vegetation in Pernambuco, Brazil. Revista Brasileira de Botânica 29: 497-508. 
Ribeiro-Filho, J. C., Palácio, H.A.Q., Andrade, E.A., Brasil, J.B. \& Araújo-Neto, J.R. 2015. Produtividade de fitomassa herbácea em diferentes manejos no semiárido cearense. Revista Agro@mbiente On-line 9: 386-396.

Rizzini, A.T. 1997. Tratado de fitogeografia do Brasil: aspectos ecológicos, sociológicos, e florísticos. Âmbito Cultural, Rio de Janeiro.

RMFC - Rede de manejo florestal da Caatinga. 2005. Protocolo de medições de parcelas permanentes. Associação plantas do Nordeste, Recife.

Rodal, M.J.N., Silva, A.C.B.L., Pessoa, L.M. \& Cavalcanti, A.D.C. 2005. Vegetação e flora fanerogâmica da área de Betânia, Pernambuco. In: F.S. Araújo, M.J.N. Rodal \& M.R.V. Barbosa (orgs.). Análise das variações da biodiversidade do bioma Caatinga: suporte a estratégias regionais de conservação. Ministério do Meio Ambiente, Brasília, pp. 139-166.

Rodal, M.J.N., Costa, K.C.C. \& Silva, A.C.B.L. 2008. Estrutura da Vegetação Caducifólia Espinhosa (Caatinga) de uma área do sertão central de Pernambuco. Hoehnea 35: 209-217.

Santos, J.M.F.F., Santos, D.M., Lopes, C.G.R., Silva, K.A., Sampaio, E.V.S.B. \& Araújo, E.L. 2013. Natural regeneration of the herbaceous community in a semiarid region in Northeastern Brazil. Environmental Monitoring and Assessment 185: 8287-8302.

Santos, L.C., Moura, V.C., Sizenando-Filho, F.A., Mesquita, L.X. \& Costa, Y.C.S. 2006. Estudo de uma flora herbácea em Jucurutú no Seridó do estado do RN. Revista Verde 1: 86-99.

SEPLAG-SE - Secretária de Estado do Planejamento Orçamento e Gestão. 2011. Sergipe em dados. SEPLAG/SUPES, Aracaju.

SEPLAG-SE - Secretária de Estado do Planejamento Orçamento e Gestão. 2014. Enciclopédia dos municípios sergipanos. SEPLAG/Observatório de Sergipe, Aracaju.

SEPLANTEC-SE - Secretaria de Estado do Planejamento e da Ciência e Tecnologia. 1997. Perfis Municipais: Poço Verde. SUPES, Aracaju.

Shepherd, G.J. 2010. Fitopac: versão 2.1.2.85. Universidade Estadual de Campinas, Campinas.

Silva, B.L.R. 2011. Estrutura e composição florística de herbáceas em diferentes estádios sucessionais de Caatinga. Dissertação de Mestrado, Universidade Federal de Pernambuco, Recife.
Silva, K.A., Araújo, E.L. \& Ferraz, E.M.N. 2009. Estudo florístico do componente herbáceo e relação com solos em áreas de Caatinga do embasamento cristalino e bacia sedimentar, Petrolândia, PE, Brasil. Acta Botanica Brasilica 23: 100-110.

Silva, B.L.R., Tavares, F.M. \& Cortez, J.S.A. 2012. Composição florística do componente herbáceo de uma área de Caatinga - fazenda Tamanduá, Paraíba, Brasil. Revista de Geografia 29: 54-64.

Silva, K.A., Santos, J.M.F.F., Santos, D.M., Ferraz, E.M.N. \& Araújo, E.L. 2013a. Spatial variation in the structure and composition of the herbaceous community in a semiarid region of northeastern Brazil. Brazilian Journal Biology 73: 135-148.

Silva, A.C.C., Prata, A.P.N. \& Mello, A.A. 2013 b. Flowering plants of the Grota do Angico Natural Monument, Caatinga of Sergipe, Brazil. Check List 9: 733-739.

Silva, K.A., Santos, J.M.F.F., Santos, D.M., Andrade, J.R., Ferraz, E.M.N. \& Araújo, E.L. 2015. Interactions between the herbaceous and shrubby-arboreal components in a semiarid region in the Northeast of Brazil: competition or facilitation? Revista Caatinga 28: $157-165$.

Sizenando-Filho, F.A., Maracajá, P.B., Diniz-Filho, E.T. \& Freitas, R.A.C. 2007. Estudo florístico e fitossociológico da flora herbácea do município de Messias Targino, RN/PB. Revista de Biologia e Ciências da Terra $7: 1-8$.

Souza, V.C. \& Lorenzi, H. 2012. Botânica Sistemática: guia ilustrado para identificação das famílias de Fanerógamas e nativas e exóticas no Brasil, baseado em APG III. Instituto Plantarum, Nova Odessa.

Thiers B. 2016. Index Herbariorum: the herbaria of the world. Disponível em http://sweetgum.nybg.org/ih/ (acesso em 15-IV-2016).

Vieira, D.L.M. \& Scariot, A. 2006. Principles of natural regeneration of tropical dry forests for restoration. Restoration Ecology 14: 11-20.

Vieira, I.C.G. \& Gardner, T.A. 2012. Florestas secundárias tropicais: ecologia e importância em paisagens antrópicas. Boletim do Museu Paraensi Emílio Goeldi 7: 191-194.

Zar, J.H. 2010. Biostatistical analysis. Prentice-Hall, New Jersey.

Zelarayán, M.L.C., Celentano, D., Oliveira, E.C., Triana, S.P., Sodré, D.N., Muchavisoy, K.H.M. \& Rousseau, G.X. 2015. Impacto da degradação sobre o estoque total de carbono de florestas ripárias na Amazônia Oriental, Brasil. Acta Amazonica 45: 271-282. 